\title{
High visceral fat with low subcutaneous fat accumulation as a determinant of atherosclerosis in patients with type 2 diabetes
}

Ryotaro Bouchi ${ }^{{ }^{* \dagger}}$, Takato Takeuchi ${ }^{1 \dagger}$, Momoko Akihisa ${ }^{1}$, Norihiko Ohara', Yujiro Nakano ${ }^{1}$, Rie Nishitani ${ }^{1}$, Masanori Murakami ${ }^{1}$, Tatsuya Fukuda ${ }^{1}$, Masamichi Fujita', Isao Minami ${ }^{1}$, Hajime Izumiyama 1,2, Koshi Hashimoto ${ }^{1,3}$, Takanobu Yoshimoto ${ }^{1}$ and Yoshihiro Ogawa ${ }^{1,4}$

\begin{abstract}
Background: Abdominal visceral obesity has been reported to be associated with cardiovascular risks than body mass index, waist circumference, and abdominal subcutaneous fat. On the other hand, there is evidence that subcutaneous fat has a beneficial role against cardio-metabolic risks such as diabetes or dyslipidemia. However, little is known regarding the association between high visceral fat with low subcutaneous fat accumulation and the risk for atherosclerosis.

Methods: This study was designed to elucidate whether high visceral fat with low subcutaneous fat accumulation enhances the risk for atherosclerosis in patients with type 2 diabetes. This is a cross-sectional study of 148 patients with type 2 diabetes (mean age $65 \pm 12$ years; $44.5 \%$ female). Visceral fat area (VFA, $\mathrm{cm}^{2}$ ) and subcutaneous fat area $\left(\mathrm{SFA}, \mathrm{cm}^{2}\right.$ ) were assessed by abdominal computed tomography. Carotid intima media thickness (CIMT, mm) measured by ultrasonography was used for the assessment of atherosclerosis. Patients were divided into four groups: SFA $<100 \mathrm{~cm}^{2}$ and VFA $<100 \mathrm{~cm}^{2}[S(-) V(-)]$, SFA $\geq 100 \mathrm{~cm}^{2}$ and VFA $<100 \mathrm{~cm}^{2}[S(+) V(-)]$, SFA $<100 \mathrm{~cm}^{2}$ and $V F A \geq 100 \mathrm{~cm}^{2}[S(-) V(+)]$, and SFA $\geq 100 \mathrm{~cm}^{2}$ and $V F A \geq 100 \mathrm{~cm}^{2}[S(+) V(+)]$. Linear regression analysis with a stepwise procedure was used for the statistical analyses.

Results: Among the patients examined, $16.3 \%$ were $\mathrm{S}(-) \mathrm{V}(+)$. Mean (95\% confidence interval) of CIMT adjusting for age and gender were $0.80(0.69-0.91), 0.86(0.72-1.01), 1.28(1.11-1.44)$ and $0.83(0.77-0.88)$ in patients with $S(-)$ $\mathrm{V}(-), \mathrm{S}(+) \mathrm{V}(-), \mathrm{S}(-) \mathrm{V}(+)$ and $\mathrm{S}(+) \mathrm{V}(+)$, respectively $(\mathrm{p}<0.001)$. The $\mathrm{S}(-) \mathrm{V}(+)$ patients exhibited significantly older than $\mathrm{S}(-) \mathrm{V}(-)$ patients and those with $\mathrm{S}(+) \mathrm{V}(+)$ and had a highest VFA-SFA ratio (V/S ratio) among the four groups. $\mathrm{S}(-) \mathrm{V}(+)$ patients were male predominant $(100 \%$ male), and $\mathrm{S}(+) \mathrm{V}(-)$ patients showed female predominance $(82 \%$ female). In multivariate linear regression analysis (Adjusted $\left.R^{2}=0.549\right), S(-) V(+)$ was significantly associated with CIMT (Standardized $\beta$ 0.423, $p<0.001$ ). Notably, $\mathrm{S}(+) \mathrm{V}(+)$ was inversely associated with CIMT in the multivariate model.

Conclusions: This study provides evidence that high visceral fat with low subcutaneous fat accumulation is an important determinant of carotid atherosclerosis and high subcutaneous fat could be protective against atherosclerosis in patients with type 2 diabetes.
\end{abstract}

\footnotetext{
*Correspondence: bouchi.mem@tmd.ac.jp

${ }^{\dagger}$ Ryotaro Bouchi and Takato Takeuchi contributed equally to this work

${ }^{1}$ Department of Molecular Endocrinology and Metabolism, Graduate

School of Medical and Dental Sciences, Tokyo Medical and Dental

University, 1-5-45 Bunkyo-ku, Yushima, Tokyo 113-8510, Japan

Full list of author information is available at the end of the article
} 
Keywords: Visceral adiposity, Subcutaneous adiposity, Atherosclerosis

\section{Background}

Obesity has been reported to be associated with insulin resistance, dyslipidemia, and hypertension, thus increasing the risk for cardiovascular disease (CVD) [1-4]. Regarding body fat distribution, abdominal visceral fat has been more strongly associated with cardiovascular risks than body mass index (BMI), waist circumference, and abdominal subcutaneous fat $[5,6]$. Therefore, evaluation and management of visceral fat accumulation is important to reduce cardio-metabolic burdens. Recently, we have reported that increased visceral fat with normal $\mathrm{BMI}$ is associated with arterial stiffening in patients with type 2 diabetes [7]. On the other hand, there is evidence that subcutaneous fat has a beneficial role against cardio-metabolic risks such as diabetes or dyslipidemia [8, 9]. These observations suggest the importance of direct evaluation of visceral and subcutaneous fat accumulation for the management of atherosclerosis; therefore it is possible that increased visceral fat with decreased subcutaneous fat accumulation is positively associated with atherosclerosis. Here we investigated the impact of body fat distribution, i.e. increased visceral fat with decreased subcutaneous fat accumulation, on carotid atherosclerosis in Japanese patients with type 2 diabetes.

\section{Methods}

\section{Subjects}

Patients with type 2 diabetes who regularly visited Tokyo Medical and Dental University Hospital participated in this study. Patients were eligible, if they were aged $\geq 20$ years, and 148 consequential patients who underwent abdominal computed tomography (CT) for the assessment of visceral and subcutaneous fat accumulation were enrolled. Patients with severe renal impairment [estimated glomerular filtration rate (eGFR) $<15 \mathrm{~mL} /$ $\min / 1.73 \mathrm{~m}^{2}$ or undergoing renal replacement therapy], pregnant women, and those with infectious or malignant diseases were excluded. Type 2 diabetes was diagnosed according to the criteria of the Japan Diabetes Society (JDS) [10]. This study complies with the principles laid by Declaration of Helsinki and has been approved by the ethical committee of Tokyo Medical and Dental University (No. 2103).

\section{Clinical and biochemical analysis}

Visceral fat area (VFA) and subcutaneous fat area (SFA) were measured at the level of umbilicus by abdominal CT examination (Aquilion PRIME, Toshiba Medical Systems, Tochigi, Japan). Atherosclerosis was assessed by carotid intima media thickness (CIMT) using an echotomographic system (Aplio XG SSA790A, Toshiba Medical Systems, Tochigi, Japan) with a $7.5-\mathrm{MHz}$ linear transducer, as reported previously [11]. Following the criteria of visceral fat obesity as recommended by the Japan Society for the Study of Obesity [12], we defined visceral and subcutaneous fat accumulation; they were classified into four groups as follows: SFA $<100 \mathrm{~cm}^{2}$ and VFA $<100 \mathrm{~cm}^{2}$ $[\mathrm{S}(-) \mathrm{V}(-)], \mathrm{SFA} \geq 100 \mathrm{~cm}^{2}$ and VFA $<100 \mathrm{~cm}^{2}[\mathrm{~S}(+)$ $\mathrm{V}(-)]$, SFA $<100 \mathrm{~cm}^{2}$ and VFA $\geq 100 \mathrm{~cm}^{2}[\mathrm{~S}(-) \mathrm{V}(+)]$ and SFA $\geq 100 \mathrm{~cm}^{2}$ and VFA $\geq 100 \mathrm{~cm}^{2}[\mathrm{~S}(+) \mathrm{V}(+)]$.

\section{Statistical analysis}

Statistical analysis was performed using programs available in the SPSS version 21.0 statistical package (SPSS Inc., Chicago, IL, USA). Data are presented as mean \pm SD or geometric mean with $95 \%$ confidence interval (CI) as appropriate according to data distribution. Differences among the four groups were tested with a one-way ANOVA (continuous variables) or Chi square test (categorical variables) followed by Tukey-Kramer methods for the post hoc analyses. Linear regression analysis with a stepwise procedure was used to assess the cross-sectional association of each manifestation of abdominal (VFA) and subcutaneous (SFA) fat accumulation with carotid atherosclerosis. The following covariates were incorporated into the analysis; age, gender, duration of diabetes, smoking status, systolic blood pressure, triglycerides, high-density lipoprotein (HDL) cholesterol, low-density lipoprotein (LDL) cholesterol, HbA1c, urinary albuminto-creatinine ratio (ACR), eGFR, and the use of insulin, the use of calcium channel blockers (CCBs), angiotensin-converting enzyme inhibitors, angiotensin receptor blockers (ARBs), statins, and anti-platelet agents. We also underwent a sensitivity analysis to examine the association of VFA and SFA with CIMT, using the cutoff of 100 and $150 \mathrm{~cm}^{2}$ in VFA and SFA, respectively, because the average of SFA in this study was approximately $150 \mathrm{~cm}^{2}$. Differences were considered to be statistically significant at $\mathrm{p}$ value less than 0.05 .

\section{Results}

A total of 148 Japanese patients with type 2 diabetes (mean age $65 \pm 12$ years; $44.5 \%$ female) were enrolled in this study. Among the participants, $16.3 \%(\mathrm{~N}=11)$ were classified as $\mathrm{S}(-) \mathrm{V}(+)$, and $23.0 \%(\mathrm{~N}=34), 26.4 \%$ $(\mathrm{N}=39)$ and $43.2 \%(\mathrm{~N}=64)$ were classified as $\mathrm{S}(-)$ $\mathrm{V}(-), \mathrm{S}(+) \mathrm{V}(-)$, and $\mathrm{S}(+) \mathrm{V}(+)$, respectively (Fig. 1). As shown in Table $1, \mathrm{~S}(-) \mathrm{V}(+)$ patients were older than 


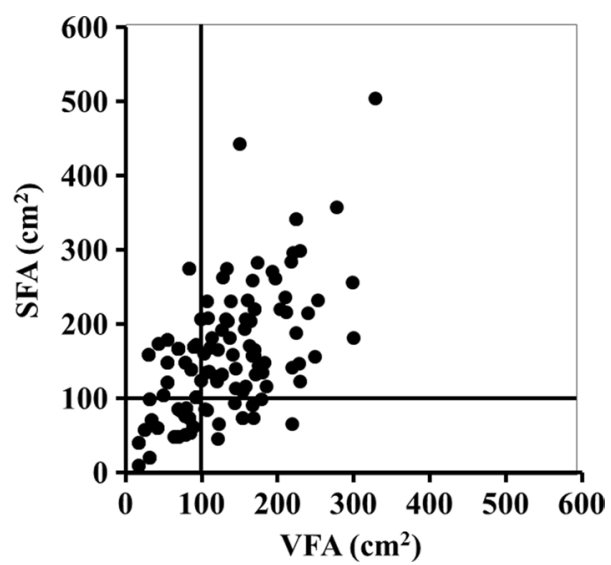

Fig. 1 The correlation between visceral fat area and subcutaneous fat area in patients with type 2 diabetes. SFA subcutaneous fat area $\left(\mathrm{cm}^{2}\right)$, VFA visceral fat area $\left(\mathrm{cm}^{2}\right)$

$\mathrm{S}(-) \mathrm{V}(-)$ patients $(\mathrm{p}=0.004)$ and $\mathrm{S}(+) \mathrm{V}(+)(\mathrm{p}=0.036)$, and had a significantly higher VFA-SFA ratio (V/S ratio) than $\mathrm{S}(-) \mathrm{V}(-)(\mathrm{p}<0.001), \mathrm{S}(+) \mathrm{V}(-)(\mathrm{p}<0.001)$, and $\mathrm{S}(+) \mathrm{V}(+)$ patients $(\mathrm{p}<0.001)$. Systolic blood pressure in $\mathrm{S}(-) \mathrm{V}(+)$ patients were significantly higher than $\mathrm{S}(-)$ $\mathrm{V}(-)(\mathrm{p}<0.001)$ and $\mathrm{S}(+) \mathrm{V}(-)$ patients $(\mathrm{p}<0.001)$. Interestingly, there were appreciable differences in gender and fat distribution between $\mathrm{S}(-) \mathrm{V}(+)$ and $\mathrm{S}(+)$ $\mathrm{V}(-)$ patients, without a significant difference in BMI. In this study, $\mathrm{S}(-) \mathrm{V}(+)$ patients were male predominant (100\% male), and $\mathrm{S}(+) \mathrm{V}(-)$ patients showed female predominance (82 \% female). Moreover, $\mathrm{S}(-) \mathrm{V}(+)$ patients had significantly higher uric acid $(\mathrm{p}<0.001)$ and glutamyl transpeptidase $(\gamma-\mathrm{GTP})(\mathrm{p}<0.001)$ levels than $\mathrm{S}(+)$ $\mathrm{V}(-)$ patients. The $\mathrm{S}(-) \mathrm{V}(+)$ patients had reached the maximum BMI at younger age (43 \pm 12 years) than $S(+)$ $\mathrm{V}(-)$ patients $(47 \pm 11$ years $)$ and $\mathrm{S}(+) \mathrm{V}(+)$ patients $(51 \pm 13$ years). The maximum BMI in $\mathrm{S}(-) \mathrm{V}(+)$ patients was significantly lower than that $\mathrm{S}(+) \mathrm{V}(-)$ and $\mathrm{S}(+) \mathrm{V}(+)$ patients (data not shown). Medications were listed in Table 2. None of $\mathrm{S}(-) \mathrm{V}(+)$ patients received biguanides nor statins, although $\mathrm{S}(-) \mathrm{V}(+)$ patients showed increased visceral fat accumulation. The number

Table 1 Clinical data of patients with type 2 diabetes

\begin{tabular}{|c|c|c|c|c|c|}
\hline \multirow{2}{*}{$\begin{array}{l}\text { VFA }\left(\mathrm{cm}^{2}\right) \\
\text { SFA }\left(\mathrm{cm}^{2}\right)\end{array}$} & \multicolumn{2}{|l|}{$<100$} & \multicolumn{2}{|l|}{$\geq 100$} & \multirow[t]{2}{*}{ p value* } \\
\hline & $<100(\mathrm{~N}=34)$ & $\geq 100(N=39)$ & $<100(\mathrm{~N}=11)$ & $\geq 100(N=64)$ & \\
\hline VFA $\left(\mathrm{cm}^{2}\right)$ & $56 \pm 26$ & $74 \pm 21$ & $149 \pm 34$ & $175 \pm 52$ & $<0.001$ \\
\hline SFA $\left(\mathrm{cm}^{2}\right)$ & $61 \pm 23$ & $157 \pm 41$ & $78 \pm 16$ & $149 \pm 34$ & $<0.001$ \\
\hline VFA-to-SFA ratio & $1.00 \pm 0.43$ & $0.50 \pm 0.20$ & $1.98 \pm 0.62$ & $0.92 \pm 0.33$ & $<0.001$ \\
\hline Age (years) & $70 \pm 10$ & $64 \pm 11$ & $72 \pm 6$ & $62 \pm 12$ & 0.001 \\
\hline Gender (\% male) & 77 & 18 & 100 & 59 & $<0.001$ \\
\hline $\mathrm{BMI}\left(\mathrm{kg} / \mathrm{m}^{2}\right)$ & $19.4 \pm 2.1$ & $23.2 \pm 2.4$ & $22.5 \pm 1.8$ & $27.0 \pm 3.8$ & $<0.001$ \\
\hline $\mathrm{SBP}(\mathrm{mmHg})$ & $118 \pm 15$ & $115 \pm 9$ & $136 \pm 13$ & $129 \pm 11$ & $<0.001$ \\
\hline $\mathrm{DBP}(\mathrm{mmHg})$ & $68 \pm 11$ & $66 \pm 9$ & $78 \pm 15$ & $75 \pm 12$ & $<0.001$ \\
\hline Current smoker (\%) & 0 & 5 & 18 & 11 & 0.111 \\
\hline Duration of diabetes (years) & $4.9(4.2-5.7)$ & $2.6(2.2-3.2)$ & $3.8(3.0-4.8)$ & $3.2(3.1-3.3)$ & 0.120 \\
\hline HbA1c (\%) & $6.9 \pm 1.0$ & $6.7 \pm 0.4$ & $6.7 \pm 0.4$ & $7.4 \pm 1.7$ & 0.024 \\
\hline Triglycerides (mmol/l) & $1.36(1.15-1.61)$ & $1.01(0.88-1.16)$ & $1.16(0.79-1.69)$ & $1.67(1.43-1.96)$ & 0.001 \\
\hline HDL cholesterol (mmol/l) & $1.48 \pm 0.52$ & $1.50 \pm 0.58$ & $1.61 \pm 0.42$ & $1.52 \pm 0.44$ & 0.900 \\
\hline LDL cholesterol (mmol/l) & $2.42 \pm 0.72$ & $2.80 \pm 1.05$ & $2.80 \pm 0.75$ & $2.95 \pm 0.82$ & 0.052 \\
\hline Uric acid ( $\mu \mathrm{mol} / \mathrm{l})$ & $282 \pm 85$ & $265 \pm 82$ & $395 \pm 91$ & $335 \pm 58$ & $<0.001$ \\
\hline eGFR (ml/min/1.73 m²) & $76.8 \pm 18.1$ & $73.0 \pm 21.5$ & $62.3 \pm 22.6$ & $70.6 \pm 23.4$ & 0.250 \\
\hline $\log A C R(m g / g)$ & $24(18-31)$ & $23(15-35)$ & $25(11-55)$ & $45(31-68)$ & $<0.001$ \\
\hline PDR (\%) & 6 & 0 & 0 & 11 & 0.128 \\
\hline AST (U/I) & $25(23-27)$ & $21(19-24)$ & $27(22-34)$ & $25(23-28)$ & 0.060 \\
\hline $\mathrm{ALT}(\mathrm{U} / \mathrm{I})$ & $21(17-25)$ & $16(14-17)$ & $21(14-31)$ & $27(23-31)$ & $<0.001$ \\
\hline$\gamma$-GTP $(\mathrm{U} / \mathrm{I})$ & $26(23-31)$ & $23(21-25)$ & $64(37-112)$ & 41 (29-59) & $<0.001$ \\
\hline CIMT (mm) & $0.86 \pm 0.17$ & $0.88 \pm 0.07$ & 1.300 .41 & $0.81 \pm 0.17$ & $<0.001$ \\
\hline
\end{tabular}

Data are expressed as mean \pm SD, geometric mean $(95 \% \mathrm{Cl})$ or percentage

$A L T$ alanine aminotransferase, AST asparatate aminotransferase, CIMT carotid intima media thickness, DBP diastolic blood pressure, eGFR estimated glomerular filtration rate, $\gamma$-GTP glutamyl transpeptidase, HDL high-density lipoprotein, $L D L$ low-density lipoprotein, PDR proliferative diabetic retinopathy, SBP systolic blood pressure

* One-way ANOVA or Chi square test 
Table 2 Medications of patients with type 2 diabetes

\begin{tabular}{|c|c|c|c|c|c|}
\hline \multirow{2}{*}{$\begin{array}{l}\text { VFA }\left(\mathrm{cm}^{2}\right) \\
\text { SFA }\left(\mathrm{cm}^{2}\right)\end{array}$} & \multicolumn{2}{|l|}{$<100$} & \multicolumn{2}{|l|}{$\geq 100$} & \multirow[t]{2}{*}{ p value* } \\
\hline & $<100(\mathrm{~N}=34)$ & $\geq 100(N=39)$ & $<100(\mathrm{~N}=11)$ & $\geq 100(N=34)$ & \\
\hline $\mathrm{OHA}(\%)$ & 41.2 & 33.3 & 54.5 & 54.7 & 0.164 \\
\hline Sulfonylureas (\%) & 25.0 & 0.0 & 12.5 & 22.4 & 0.055 \\
\hline Biguanides (\%) & 16.7 & 15.4 & 0.0 & 40.8 & 0.012 \\
\hline Alpha-Gls (\%) & 25.0 & 0.0 & 12.5 & 10.2 & 0.048 \\
\hline TZDs (\%) & 8.3 & 0.0 & 7.7 & 6.1 & 0.301 \\
\hline DPP4 inhibitors (\%) & 25.0 & 42.3 & 62.5 & 34.7 & 0.245 \\
\hline Glinides (\%) & 8.3 & 0.0 & 0.0 & 0.0 & 0.070 \\
\hline GLP-1 agonists (\%) & 0.0 & 0.0 & 0.0 & 2.0 & 0.754 \\
\hline Insulin (\%) & 41.2 & 38.5 & 18.2 & 35.9 & 0.575 \\
\hline ACEIs (\%) & 0.0 & 5.4 & 0.0 & 3.2 & 0.516 \\
\hline ARBs (\%) & 17.6 & 24.3 & 45.5 & 44.4 & 0.025 \\
\hline CCBs $(\%)$ & 11.8 & 5.4 & 36.4 & 30.2 & 0.007 \\
\hline Beta blockers (\%) & 5.9 & 18.9 & 18.2 & 14.3 & 0.424 \\
\hline Alpha blockers (\%) & 0.0 & 5.4 & 0.0 & 1.6 & 0.383 \\
\hline Diuretics (\%) & 5.9 & 24.3 & 9.1 & 11.1 & 0.110 \\
\hline Statins (\%) & 11.8 & 16.2 & 0.0 & 34.9 & 0.007 \\
\hline Fibrates (\%) & 0.0 & 0.0 & 0.0 & 3.2 & 0.451 \\
\hline UA-lowering agents & 0.0 & 10.8 & 9.1 & 6.3 & 0.289 \\
\hline Anti-platelets (\%) & 11.8 & 0.0 & 9.1 & 12.7 & 0.168 \\
\hline
\end{tabular}

Data are expressed as percentage

$A C E l$ angiotensin-converting enzyme inhibitor, $A R B$ angiotensin receptor blocker, $C C B$ calcium channel blocker, DPP4 dipeptidyl peptidase-4, GI glycosidase inhibitor, GLP-1 glucagon-like peptide-1, OHA oral hypoglycemic agent, TZD thiazolidinedione, UA uric acid

* Chi square test

of $\mathrm{S}(+) \mathrm{V}(+)$ patients taking biguanides and statins was greater than those of $\mathrm{S}(-) \mathrm{V}(-), \mathrm{S}(+) \mathrm{V}(-)$, and $\mathrm{S}(+) \mathrm{V}(+)$ patients.

As expected, $\mathrm{S}(-) \mathrm{V}(+)$ patients had the highest CIMT level among the four groups [vs. $\mathrm{S}(-) \mathrm{V}(-)(\mathrm{p}<0.001)$, vs. $\mathrm{S}(+) \mathrm{V}(-)(\mathrm{p}<0.001)$, vs. $\mathrm{S}(+) \mathrm{V}(+)(\mathrm{p}<0.001)]$ (Table 1$)$. After adjustment for age and gender, mean (95\% CI) of CIMT were 0.80 (0.69-0.91), 0.86 (0.72-1.01), 1.28 $(1.11-1.44)$ and $0.83(0.77-0.88)$ in patients with $\mathrm{S}(-)$ $\mathrm{V}(-), \mathrm{S}(+) \mathrm{V}(-), \mathrm{S}(-) \mathrm{V}(+)$ and $\mathrm{S}(+) \mathrm{V}(+)$, respectively $(\mathrm{p}<0.001)$. On the other hand, CIMT level in $\mathrm{S}(+) \mathrm{V}(+)$ patients was roughly equivalent to those in $\mathrm{S}(-) \mathrm{V}(-)$ and $\mathrm{S}(+) \mathrm{V}(-)$ patients. In the univariate analysis, $\mathrm{S}(-)$ $\mathrm{V}(+)$ was significantly associated with CIMT (standardized $\beta$ 0.531, $\mathrm{p}<0.001)$; whereas $\mathrm{S}(+) \mathrm{V}(-)$ and $\mathrm{S}(+) \mathrm{V}(+)$ were not associated with CIMT (Table 3). In the multivariate analysis, $\mathrm{S}(-) \mathrm{V}(+)$ remained to be significantly associated with the risk for CIMT (standardized $\beta$ 0.423, $\mathrm{p}<0.001$ ). Adjusted $\mathrm{R}^{2}$ was 0.549 in the model. Notably, $\mathrm{S}(+) \mathrm{V}(+)$ was inversely associated with CIMT in the multivariate model. Using V/S ratio as the indicator for balance of visceral and subcutaneous fat accumulation, we also examined whether increased visceral fat relative to subcutaneous fat is continuously associated with CIMT. In this study, V/S ratio showed significantly positive correlations with CIMT in both univariate (Standardized $\beta$ $0.506, \mathrm{p}<0.001)$ and multivariate linear regression analyses (Standardized $\beta$ 0.383, $\mathrm{p}<0.001$ ). We finally underwent a sensitivity analysis using the cutoff of $150 \mathrm{~cm}^{2}$ for SFA because the average of SFA in this study was approximately $150 \mathrm{~cm}^{2}$. In the multivariate linear regression analysis, the association between SFA $<150 \mathrm{~cm}^{2}$ and VFA $\geq 100 \mathrm{~cm}^{2}$ and CIMT as compared with SFA $<150 \mathrm{~cm}^{2}$ and VFA $<100 \mathrm{~cm}^{2}$ reached a marginal statistical significance (Standardized $\beta$ 0.190, $\mathrm{p}=0.051$ ); whereas, patients with SFA $\geq 150 \mathrm{~cm}^{2}$ and VFA $\geq 100 \mathrm{~cm}^{2}$ were not significantly increased risk for CIMT.

\section{Discussion}

Here, we demonstrate that $\mathrm{S}(-) \mathrm{V}(+)$ patients are at an significantly increased risk for carotid atherosclerosis among Japanese patients with type 2 diabetes. Moreover, in multivariate analyses, there was a direct relationship between the presence of $\mathrm{S}(-) \mathrm{V}(+)$ and risk for atherosclerosis and an inverse relationship between the presence of $\mathrm{S}(+) \mathrm{V}(+)$ and risk for CIMT. 
Table 3 Linear regression analysis for risk factors of intima media thickness in patients with type 2 diabetes

\begin{tabular}{|c|c|c|}
\hline & Standardized $\beta$ & $p$ values \\
\hline \multicolumn{3}{|l|}{ Univariates } \\
\hline $\begin{array}{l}\text { SFA } \geq 100 \mathrm{~cm}^{2} \text { and } V F A<100 \mathrm{~cm}^{2}[S(+) \\
\quad V(-)]\end{array}$ & 0.032 & 0.813 \\
\hline $\begin{array}{l}\text { SFA }<100 \mathrm{~cm}^{2} \text { and } \mathrm{VFA} \geq 100 \mathrm{~cm}^{2}[\mathrm{~S}(-) \\
\quad \mathrm{V}(+)]\end{array}$ & 0.531 & $<0.001$ \\
\hline $\begin{array}{l}\text { SFA } \geq 100 \mathrm{~cm}^{2} \text { and } V F A \geq 100 \mathrm{~cm}^{2}[S(+) \\
V(+)]\end{array}$ & -0.128 & 0.359 \\
\hline \multicolumn{3}{|l|}{ Multivariates } \\
\hline $\begin{array}{l}\text { SFA } \geq 100 \mathrm{~cm}^{2} \text { and } V F A<100 \mathrm{~cm}^{2}[S(+) \\
V(-)]\end{array}$ & -0.100 & 0.386 \\
\hline $\begin{array}{l}\mathrm{SFA}<100 \mathrm{~cm}^{2} \text { and } \mathrm{VFA} \geq 100 \mathrm{~cm}^{2}[\mathrm{~S}(-) \\
\quad \mathrm{V}(+)]\end{array}$ & 0.423 & $<0.001$ \\
\hline $\begin{array}{l}S F A \geq 100 \mathrm{~cm}^{2} \text { and } V F A \geq 100 \mathrm{~cm}^{2}[S(+) \\
V(+)]\end{array}$ & -0.319 & 0.009 \\
\hline Age & 0.575 & $<0.001$ \\
\hline Urinary ACR & 0.299 & 0.001 \\
\hline CCBs & -0.171 & 0.023 \\
\hline Duration of diabetes & 0.156 & 0.049 \\
\hline
\end{tabular}

Covariates; age, gender, history of cardiovascular disease, systolic blood pressure, duration of diabetes, current smoking, $\mathrm{HbA} 1 \mathrm{c}$, low-density lipoprotein cholesterol, high-density lipoprotein cholesterol, logarithmically transformed triglycerides, C-reactive protein, eGFR, albuminuria, the use of insulin, oral hypoglycemic agents, renin-angiotensin system blockers, calcium channel blockers and statins

$A C R$ albumin-to-creatinine ratio, CCB calcium channel blocker, SFA subcutaneous fat area, VFA visceral fat area

\section{The association between body fat accumulation and atherosclerosis}

Visceral adipose tissue has been recently reported to be associated with coronary plaque characteristics in patients without diabetes [13] and visceral adipose tissue is a stronger risk factor of carotid atherosclerosis in Chinese adults [14]. Therefore, our data support the notion that visceral fat accumulation is positively associated with atherosclerosis. By contrast, Ravussin and Smith $[15,16]$ proposed the possibility that the ability to retain fat in subcutaneous depot is beneficial against cardiometabolic risks. In addition, a more recent study clearly revealed that subcutaneous adipose thickness assessed by ultrasonography is inversely associated with carotid atherosclerosis in patients with type 2 diabetes [17]. These observations taken together, suggest that body fat distribution should be evaluated with information on visceral and subcutaneous fat accumulation for the assessment of the risks for atherosclerosis.

\section{Possible factors associated with fat distribution and atherosclerosis}

In this study, $\mathrm{S}(-) \mathrm{V}(+)$ patients were elderly men with severe cardio-metabolic profiles, including elevated blood pressure and uric acid, and high $\mathrm{V} / \mathrm{S}$ ratio. These observations may partly explain the progression of atherosclerosis in $\mathrm{S}(-) \mathrm{V}(+)$ patients. In addition, $\mathrm{S}(-) \mathrm{V}(+)$ patients had reached maximum BMI at younger age than $\mathrm{S}(+) \mathrm{V}(-)$ and $\mathrm{S}(+) \mathrm{V}(+)$ patients. The maximum BMI in $\mathrm{S}(-) \mathrm{V}(+)$ patients was low relative to $\mathrm{S}(+) \mathrm{V}(-)$ and $\mathrm{S}(+) \mathrm{V}(+)$ patients. It is interesting to speculate that $\mathrm{S}(-)$ $\mathrm{V}(+)$ patients have lower capacity to store excess energy in subcutaneous fat depot than $\mathrm{S}(+) \mathrm{V}(-)$ and $\mathrm{S}(+) \mathrm{V}(+)$ patients. Then, what could affect body fat distribution? A recent large scale cross-sectional study demonstrated that abdominal adiposity is positively associated with a deteriorated cardio-metabolic risk profile in multi-ethnicities and that East Asians have the highest visceral relative to subcutaneous fat accumulation among whites, African Caribbean blacks, Hispanics, East Asians, and Southeast Asians [18]. The Japanese men are likely to have a greater percent body fat than Australian men at any given BMI values [19]. Gender is also an important determinant of body fat distribution. Indeed, a genomewide association study meta-analysis showed sexual dimorphism in the genetic regulation of fat distribution traits [20]. In this study, there was a clear gender difference in body fat distribution, with male predominance in $\mathrm{S}(-) \mathrm{V}(+)$ and female predominance in $\mathrm{S}(+) \mathrm{V}(-)$. It has been observed that high fat stores in ectopic fat compartments including skeletal muscle are present in male patients newly diagnosed with type 2 diabetes and altered lipid partitioning within muscle is independently associated with carotid atherosclerosis [21]. Després has recently proposed the lipid overflow-ectopic fat model [22]. If the extra energy is channeled into insulin-sensitive subcutaneous adipose tissue, the subjects will be protective against the development of the metabolic syndrome; whereas, in cases where the adipose tissue has a limited ability to store the excess energy into subcutaneous adipose tissue, triglycerides surplus will be deposited at undesirable sites such as skeletal muscle and visceral adipose tissue, leading the insulin resistance, atherogenic dyslipidemia, and atherosclerosis. Therefore, it is possible that low capacity of subcutaneous fat accumulation in patients with $\mathrm{S}(-) \mathrm{V}(+)$ could allow ectopic fat accumulation within muscle as well as visceral fat accumulation, consequently leading to increased risk for carotid atherosclerosis. It remains to be determined whether the association observed between $\mathrm{S}(-) \mathrm{V}(+)$ and atherosclerosis in Japanese subjects with type 2 diabetes will also be observed in other populations.

\section{Limitations}

There are a couple of limitations in this study. First, it is impossible to infer causality because of its cross-sectional design. Second, we evaluated visceral fat and subcutaneous fat accumulation using VFA and SFA at the level of 
umbilicus; therefore, fat accumulation in other fat depots such as thighs and legs were not evaluated. Third, population in this study was ethnically and socially homogeneous, because this study was hospital-based; therefore, generalization of our findings might be limited. Fourth, we were unable to obtain information on diet and exercise in this study. These lifestyle could affect the distribution of body fat and BMI levels and could be one of the variables that is accounting for this high risk of CIMT in patients with $\mathrm{S}(-) \mathrm{V}(+)$. Finally, it is important to undergo the sub-analyses to investigate the association of VFA and SFA accumulation with CIMT in different age groups, gender, and metabolic status; however, we could not undergo the analyses due to the relatively small sample size.

\section{Conclusions}

It is of primary importance to identify diabetic patients who have advanced atherosclerosis because they are at extremely increased risk for CVD [23, 24]. Our data suggest that imbalance of visceral and subcutaneous fat distribution, i.e. increased visceral fat with decreased subcutaneous fat accumulation, is an important determinant of atherosclerosis, whereas increased subcutaneous fat accumulation could buffer the deleterious effect of visceral fat accumulation in patients with type 2 diabetes.

\section{Abbreviations}

ACEl: angiotensin-converting enzyme inhibitor; ACR: albumin-to-creatinine ratio; ALT: alanine aminotransferase; ARB: angiotensin receptor blocker; AST asparatate aminotransferase; BMl: body mass index; CCBs: calcium channel blockers; Cl: confidence interval; CIMT: carotid intima media thickness; $C T$ : computed tomography; CVD: cardiovascular disease; DBP: diastolic blood pressure; DPP4: dipeptidyl peptidase-4; eGFR: estimated glomerular filtration rate; Gl: glycosidase inhibitor; GLP-1: glucagon-like peptide-1; GTP: glutamyl transpeptidase; HDL: high-density lipoprotein; JDS: Japan Diabetes Society; LDL: low-density lipoprotein; OHA: oral hypoglycemic agent; PDR: proliferative diabetic retinopathy; SBP: systolic blood pressure; SFA: subcutaneous fat area; TZD: thiazolidinedione; UA: uric acid; VFA: visceral fat area.
\end{abstract}

\section{Authors' contributions}

$T T, R B$ and $Y O$ designed the study, researched data, and wrote and edited the manuscript. RB, IM, TY, and YO contributed to intellectual discussion and reviewed and edited the manuscript. MA, MF, TF, MM, RN, YN, NO, HI and $\mathrm{KH}$ researched data. As the corresponding author and guarantor of this manuscript, RB is the guarantor of this work and, as such, had full access to all the data in the study and takes responsibility for the integrity of the data and the accuracy of the data analysis. All authors read and approved the final manuscript.

\footnotetext{
Author details

${ }^{1}$ Department of Molecular Endocrinology and Metabolism, Graduate School of Medical and Dental Sciences, Tokyo Medical and Dental University, 1-5-45 Bunkyo-ku, Yushima, Tokyo 113-8510, Japan. ${ }^{2}$ Center for Medical Welfare and Liaison Services, Tokyo Medical and Dental University, Tokyo, Japan. ${ }^{3}$ Department of Preemptive Medicine and Metabolism, Graduate School of Medical and Dental Sciences, Tokyo Medical and Dental University, Tokyo, Japan. ${ }^{4}$ CREST, Japan Agency for Medical Research and Development, Tokyo, Japan.
}

\section{Acknowledgements}

This work was supported in part by Grants-in-Aid for Scientific Research from the Ministry of Education, Culture, Sports, Science and Technology of Japan. The authors thank all the staff of Department of Molecular Endocrinology and Metabolism, Tokyo Medical and Dental University and Ochanomizu Surugadai Clinic for their contributions.

\section{Competing interests}

The authors declare that they have no competing interests.

Received: 10 September 2015 Accepted: 2 October 2015

Published online: 07 October 2015

\section{References}

1. Yusuf S, Hawken S, Ounpuu S, Bautista L, Franzosi MG, Commerford P, Lang CC, Rumboldt Z, Onen CL, Lisheng L, INTERHEART Study Investigators, et al. Obesity and the risk of myocardial infarction in 27,000 participants from 52 countries: a case-control study. Lancet. 2005;366:1640-9.

2. Fujimoto WY, Bergstrom RW, Boyko EJ, Chen KW, Leonetti DL, NewellMorris L, Shofer JB, Wahl PW. Visceral adiposity and incident coronary heart disease in Japanese-American men. The 10-year follow-up results of the Seattle Japanese-American Community Diabetes Study. Diabetes Care. 1999;22:1808-12.

3. Britton KA, Massaro JM, Murabito JM, Kreger BE, Hoffmann U, Fox CS. Body fat distribution, incident cardiovascular disease, cancer, and allcause mortality. J Am Coll Cardiol. 2013;62:921-5.

4. Kanai H, Matsuzawa Y, Kotani K, Keno Y, Kobatake T, Nagai Y, Fujioka S, Tokunaga K, Tarui S. Close correlation of intra-abdominal fat accumulation to hypertension in obese women. Hypertension. 1990;16:484-90.

5. Després JP, Lemieux S, Lamarche B, Prud'homme D, Moorjani S, Brun LD, Gagné C, Lupien PJ. The insulin resistance-dyslipidemic syndrome: contribution of visceral obesity and therapeutic implications. Int J Obes Relat Metab Disord. 1995;19(Suppl 1):S76-86.

6. Fox CS, Massaro JM, Hoffmann U, Pou KM, Maurovich-Horvat P, Liu CY, Vasan RS, Murabito JM, Meigs JB, Cupples LA, et al. Abdominal visceral and subcutaneous adipose tissue compartments: association with metabolic risk factors in the Framingham Heart Study. Circulation. 2007;116:39-48.

7. Bouchi R, Minami I, Ohara N, Nakano Y, Nishitani R, Murakami M, Takeuchi T, Akihisa M, Fukuda T, Fujita M, et al. Impact of increased visceral adiposity with normal weight on the progression of arterial stiffness in Japanese patients with type 2 diabetes. BMJ Open Diabetes Res Care. 2015;3:e000081.

8. Snijder MB, Visser M, Dekker JM, Goodpaster BH, Harris TB, Kritchevsky SB, De Rekeneire N, Kanaya AM, Newman AB, Tylavsky FA, et al. Low subcutaneous thigh fat is a risk factor for unfavourable glucose and lipid levels, independently of high abdominal fat. The Health ABC Study. Diabetologia. 2005;48:301-8.

9. Porter SA, Massaro JM, Hoffmann U, Vasan RS, O'Donnel CJ, Fox CS. Abdominal subcutaneous adipose tissue: a protective fat depot? Diabetes Care. 2009:32:1068-75.

10. Committee of the Japan Diabetes Society on the Diagnostic Criteria of Diabetes Mellitus. Report of the committee on the classification and diagnostic criteria of diabetes mellitus. J Diabetes Investig. 2010;1:212-28.

11. Ito H, Komatsu Y, Mifune M, Antoku S, Ishida H, Takeuchi Y, Togane M. The estimated GFR, but not the stage of diabetic nephropathy graded by the urinary albumin excretion, is associated with the carotid intima-media thickness in patients with type 2 diabetes mellitus: a cross-sectional study. Cardiovasc Diabetol. 2010;9:18.

12. Examination Committee of Criteria for 'Obesity Disease' in Japan. Japan Society for the Study of Obesity. Circ J. 2002;66:987-92.

13. Osawa K, Miyoshi T, Koyama Y, Sato S, Akagi N, Morimitsu Y, Kubo M, Sugiyama H, Nakamura K, Morita H, et al. Differential association of visceral adipose tissue with coronary plaque characteristics in patients with and without diabetes mellitus. Cardiovasc Diabetol. 2014;13:61.

14. Ren C, Zhang J, Xu Y, Xu B, Sun W, Sun J, Wang T, Xu M, Lu J, Wang W, et al. Association between carotid intima-media thickness and index of central 
fat distribution in middle-aged and elderly Chinese. Cardiovasc Diabetol. 2014;13:139.

15. Ravussin E, Smith SR. Increased fat intake, impaired fat oxidation, and failure of fat cell proliferation result in ectopic fat storage, insulin resistance, and type 2 diabetes mellitus. Ann N Y Acad Sci. 2002;967:363-78.

16. Yang $X$, Smith U. Adipose tissue distribution and risk of metabolic disease: does thiazolidinedione-induced adipose tissue redistribution provide a clue to the answer? Diabetologia. 2007;50:1127-39.

17. Jung $\mathrm{CH}$, Kim BY, Kim KJ, Jung SH, Kim CH, Kang SK, Mok JO. Contribution of subcutaneous abdominal fat on ultrasonography to carotid atherosclerosis in patients with type 2 diabetes mellitus. Cardiovasc Diabetol. 2014;13:67.

18. Nazare JA, Smith JD, Borel AL, Haffner SM, Balkau B, Ross R, Massien C, Alméras N, Després JP. Ethnic influences on the relations between abdominal subcutaneous and visceral adiposity, liver fat, and cardiometabolic risk profile: the International Study of Prediction of Intra-Abdominal Adiposity and Its Relationship With Cardiometabolic Risk/Intra-Abdominal Adiposity. Am J Clin Nutr. 2012;96:714-26.

19. Kagawa M, Kerr D, Uchida H, Binns CW. Differences in the relationship between $\mathrm{BMI}$ and percentage body fat between Japanese and Australian-Caucasian young men. Br J Nutr. 2006;95:1002-7.
20. Shungin D, Winkler TW, Croteau-Chonka DC, Ferreira T, Locke AE, Mägi R, Strawbridge RJ, Pers TH, Fischer K, Justice AE, et al. New genetic loci link adipose and insulin biology to body fat distribution. Nature. 2015:518:187-96.

21. Kim SK, Park SW, Hwang IJ, Lee YK, Cho YW. High fat stores in ectopic compartments in men with newly diagnosed type 2 diabetes: an anthropometric determinant of carotid atherosclerosis and insulin resistance. Int J Obes (Lond). 2010;34:105-10.

22. Després JP. Body fat distribution and risk of cardiovascular disease: an update. Circulation. 2012;126:1301-13.

23. Yamasaki Y, Kodama M, Nishizawa H, Sakamoto K, Matsuhisa M, Kajimoto Y, Kosugi K, Shimizu Y, Kawamori R, Hori M. Carotid intima-media thickness in Japanese type 2 diabetic subjects: predictors of progression and relationship with incident coronary heart disease. Diabetes Care. 2000;23:1310-5.

24. Bernard S, Sérusclat A, Targe F, Charrière S, Roth O, Beaune J, Berthezène F, Moulin P. Incremental predictive value of carotid ultrasonography in the assessment of coronary risk in a cohort of asymptomatic type 2 diabetic subjects. Diabetes Care. 2005;28:1158-62.

\section{Submit your next manuscript to BioMed Central and take full advantage of:}

- Convenient online submission

- Thorough peer review

- No space constraints or color figure charges

- Immediate publication on acceptance

- Inclusion in PubMed, CAS, Scopus and Google Scholar

- Research which is freely available for redistribution

Submit your manuscript at 